\title{
Advancing Behavioral Health Literacy
}

\author{
James Scollione, $\mathrm{PhD}$ \\ Drury University, Springfield, Missouri, United States \\ (iD) https://orcid.org/oooo-0002-4847-397X
}

Contact: jscollione@drury.edu

\begin{abstract}
Accessing, comprehending, and using information to make informed decisions and improve one's overall health or well-being are the foci of health literacy. The concept of behavioral health was introduced in the early 1980 s and, since then, it has influenced new ideas (e.g., behavioral health literacy and integrated behavioral health care) and gained research and public attention. My aim is to provide an overview of definitions (i.e., health literacy, mental health literacy, and behavioral health literacy) and their connection to each other. I propose an expanded and honed definition of behavioral health literacy to enhance the behavioral health literacy and well-being of the individual as well as the community, with the hope of reducing both physical and behavioral negative health conditions and improving overall quality of life for all people.
\end{abstract}

Keywords: behavioral health, mental health, substance use disorders, co-occurring disorders, behavioral health literacy, mental illness, addiction, literacy, competency, awareness, definition, integrated health literacy, integrated care, integrated behavioral health care

Date Submitted: June 7, 2021 | Date Published: October 12, 2021

\section{Recommended Citation}

Scollione, J. (2021). Advancing behavioral health literacy. Journal of Social, Behavioral, and Health Sciences, 15(1), 231243. https://doi.org/10.5590/JSBHS.2021.15.1.16

\section{Introduction}

Mental and substance use disorders, as well as their disease burdens have increased approximately $13 \%$ in the past decade (World Health Organization, n.d.). Drug use has increased roughly 22\% since 2010 (United Nations Office on Drugs and Crime, 2021), and the recent COVID-19 pandemic has had an impact on behavioral health and services (Egede et al., 2021; WHO, 2020). Given these trends, both primary care and behavioral health care researchers and practitioners have reason to be concerned for the overall well-being of individuals and the community at large. The literature shows a well-documented association between physical health and behavioral health (Mancini, 2021; Ohrnberger et al., 2017; Walker \& Druss, 2018). Poor behavioral health increases one's risk for developing physical health conditions; equally, poor physical health increases one's risk for developing behavioral health conditions (Butler et al., 2008; Osborn, 2001; Robson \& Gray, 2007; Scott \& Happell, 2011; Scott et al., 2009, 2016). What were once considered separate health matters, and addressed individually, are now considered a mutual affair requiring collaborative care in time, research, and experience. In this paper, I will review the historical development of health literacy, mental health literacy, and behavioral health literacy and explain their interconnectedness. Finally, I offer a new and robust 
definition to enhance one's behavioral health literacy and well-being as well as that of the community, with the hope of reducing both physical and behavioral negative health conditions and improving the overall quality of life for the benefit of all people.

\section{Historical Background of Behavioral Health Literacy}

To conceptualize a new definition of behavioral health literacy, it is important to examine the development of behavioral health literacy, beginning with the definition of literacy.

\section{Defining Literacy}

The word literacy is derived from the Latin litteratus, meaning lettered; learned, liberally educated; of or belonging to learning, learned (Lewis \& Short, 1879). Therefore, literacy can be understood to mean the state of being learned, literate, or educated. The question becomes: learned, literate, or educated in what? Literacy is commonly associated with one's language, such as speaking, listening, phonics, grammar, reading, writing, and comprehension. The United Nations Educational, Scientific and Cultural Organization (2017) defines literacy as

the ability to identify, understand, interpret, create, communicate, and compute, using printed and written materials associated with various contexts. Literacy involves a continuum of learning in enabling individuals to achieve his or her goals, develop his or her knowledge and potential, and participate fully in community and wider society. (p. 14)

There are different kinds of literacy outside language, since literacy means the state of being learned, literate, or educated. These types of literacy include, but are not limited to, health literacy (Liu et al., 2020; Simonds, 1974); media literacy (Hobbs \& Jensen, 2009); computer, information systems, and information literacy (Stair \& Reynolds, 2016); economic and financial literacy (Chytilova, 2018; Organization for Economic Cooperation and Development, 2005); digital competence and digital literacy (Spante et al., 2018); civic and social literacy (Milner, 2002; Scott, 2000); environmental literacy (Aindrila, 2020; Scholz, 2011); emotional literacy (Bocchino, 1999; Steiner \& Perry, 1999; Weare, 2004); spiritual literacy (Brussat \& Brussat, 1996; Holmberg et al., 2021; King, 2013); and occupational literacy (Pollard \& Sakellariou, 2012). Behavioral health literacy has its roots in health literacy.

\section{Health Literacy}

The word health is derived from the Anglo-Saxon hāl, meaning whole, entire, uninjured, healthy, well, sound, safe, genuine, and straightforward (Hall, 1894). Therefore, health can be understood to mean the state of being healthy, whole, or sound, thus absence from illness or disorder. Health can also be understood as the interconnectedness and well-being of the mind, the body, and the soul (Bryson, 1999). There is a relationship between inadequate health literacy, poor health, health behaviors, and early death (Zarcadoolas et al., 2006). The term "health literacy" was introduced in the 1970s regarding health education. Simonds (1974) offered the following three propositions regarding new health education.

The expansion or alteration of systems for provision of health care without adequate integration of health education as a part of quality health care would be socially irresponsible. Systems for educating the children and youth of this nation can no longer avoid their responsibilities for health education without being charged with negligence. Systems for mass communications are expanding so rapidly that their further development without a sufficient commitment to health education represents a misuse of the public trust. (p. 3)

Simonds argued that the healthcare system, the education system, and the mass communication system are interconnected and share responsibility to ensure the well-being of the population. He concluded, "policies 
need to be made and implemented in all these areas, for they would provide mutual reinforcement with the likely end that we will have a healthier population" (p. 9). Refinements of health literacy have occurred since Simonds' introduction, and efforts have been made (and continue to be made) to achieve a universal definition, develop a measurement tool, enhance research, and implement interventions (Geboers et al., 2018; Huhta et al., 2018; Logan \& Siegel, 2017; Peerson \& Saunders, 2009; Sorensen et al., 2012). Health literacy would go on to influence the development of mental health literacy.

\section{Mental Health Literacy}

The word mental is derived from the Latin mens, meaning the mind, disposition, feeling, character; feelings, sentiments; the heart, soul; the conscience; the intellectual faculties, the mind, understanding, intellect, reason, judgment, discernment, consideration, reflection, intention, etc. (Lewis \& Short, 1879). Therefore, mental can be understood to mean the faculties of the mind or mental faculties. The term "mental health literacy" was first introduced in the 1990s. Jorm et al. (1997) defined mental health literacy as "the knowledge and beliefs about mental disorders which aid their recognition, management, and prevention" (p. 182). Jorm (2000) defined the attributes of mental health literacy as

the ability to recognise specific disorders or different types of psychological distress; knowledge and beliefs about risk factors and causes; knowledge and beliefs about self-help interventions; knowledge and beliefs about professional help available; attitudes which facilitate recognition and appropriate helpseeking; and knowledge of how to seek mental health information. (p. 396)

The principle of mental health literacy was (and is) the same as health literacy. Mental health-literate individuals will understand which factors are influencing their mental health and will know how to address those factors appropriately. Additionally, mental health-literate individuals will have the ability to take personal responsibility for their own mental health and for the mental health of their family and community. In fact, there is a relationship between health literacy and mental health literacy, and health literacy may be the strongest predictor of mental health literacy (Lee et al., 2020).

Mental health literacy has its challenges with conceptualization, achieving a universal definition, measurement, and inconsistencies like health literacy (Mansfield et al., 2020; Spiker \& Hammer, 2019). O'Connor et al. (2014) found that information concerning sample, measure development, and psychometric property testing was limited in 13 research studies, thus limiting the measurement of mental health literacy and lacking a robust measurement tool. Consequently, O'Connor and Casey (2015) developed the Mental Health Literacy Scale to remedy the shortcomings of previous research studies regarding the definition, sample, measurement development, and psychometric testing of mental health literacy. Several mental health literacy instruments exist, and these instruments examine knowledge (i.e., mental illness identification, and factual knowledge of mental disorders, such as terminology, etiology, diagnosis, prognosis, and consequences), stigma (i.e., stigma against mental illness or the mentally ill, self-stigma, experienced stigma, and stigma against mental health treatment and help-seeking), help-seeking (i.e., help-seeking attitudes, intentions to seek help, and actual helpseeking behaviors), and general and specific populations (Wei et al., 2015). Mental health is one aspect of behavioral health, and it should be incorporated into behavioral health literacy.

\section{Behavioral Health Literacy}

The word behavioral stems from behave, which is derived from the Anglo-Saxon behabban, meaning to include, hold, encompass, surround, comprehend, contain, restrain, detain (Hall, 1894). Therefore, behavioral can be understood to mean how one holds, contains, restrains, detains, or conducts himself or herself. The term behavioral health was first introduced in the 1980s. Matarazzo (1980) defined behavioral health as 
an interdisciplinary field dedicated to promoting a philosophy of health that stresses individual responsibility in the application of behavioral and biomedical science knowledge and techniques to the maintenance of health and the prevention of illness and dysfunction by a variety of self-initiated individual or shared activities. (p. 813)

Behavioral health and its definition were stimulated by "an emerging new specialty in behavioral medicine," as Matarazzo saw it at the time, and he trusted others would refine his definition (p. 813).

Over time, behavioral health has come to mean the combination of the fields of mental health and addictive behaviors (e.g., substances, gambling, etc.) since Matarazzo's introduction (Belar et al., 2003; National Academies of Sciences, Engineering, and Medicine, 2019). For example, the Substance Abuse and Mental Health Services Administration (2014) defined behavioral health as

a state of mental/emotional being and/or choices and actions that affect wellness. Behavioral health problems include substance abuse or misuse, alcohol and drug addiction, serious psychological distress, suicide, and mental and substance use disorders. This includes a range of problems from unhealthy stress to diagnosable and treatable diseases like serious mental illness and substance use disorders, which are often chronic in nature but from which people can and do recover. (p. xvi)

Behavioral health led to the development of the term "behavioral health care." To integrate the fields of primary care and behavioral health care and to create universal or common concepts and terminology for effective communication for all stakeholders, The Lexicon for Behavioral Health and Primary Care Integration defined behavioral health care as

an umbrella term for care that addresses behavioral problems bearing on health, including patient activation and health behaviors, mental health conditions, substance use, and other behaviors that bear on health. In this sense, behavioral healthcare is the job of all kinds of care settings, and is done by clinicians and health coaches of various disciplines or training, including but not limited to mental health professionals. It is a competency of clinics, not only of individuals. (Peek \& NIAC, 2014, p. 44)

The literature is filled with various definitions of behavioral health and behavioral health care, though these definitions tend to have the same elements with reference to mental health and addictive behaviors; however, what is lacking in the literature is a definition of behavioral health literacy.

A few efforts have been made to define behavioral health literacy. For example, drawing elements from health literacy and mental health literacy, Willis and O'Donohue (2018) defined behavioral health literacy, for both provider and patient, as

the ability to obtain valid and relevant behavioral health information, often with consultation with healthcare professionals; the ability to evaluate and synthesize the obtained behavioral health information; the ability to use that information to make sound behavioral healthcare decisions relating to both wellness and the treatment of illness (this includes an understanding of important treatment factors such as duration, safety, possible side effects, and costs); the ability to understand the factors that contribute to prevention of psychological disorders and the promotion of overall wellness; being able to recognize when a disorder is beginning or worsening; how to prevent behavioral health disorders; knowledge of effective and safe treatment options; and understanding of stepped care in behavioral health, including effective self-help strategies for managing behavioral health issues and knowing when to seek higher levels of care; and how to successfully access treatment options, including where those options are located, who are competent providers, and how services can be obtained (e.g., insurance vs. self-pay vs. free clinics, etc.). (pp. 155-156) 
Green et al. (2020) used Jorm's (2000) attributes of mental health literacy to define behavioral health literacy. The attributes of mental health literacy that they used in their research study were (a) the ability to recognize a mental disorder, (b) knowledge and beliefs about help sources, and (c) knowledge of how to seek mental health information (Green et al., 2020, p. 3; Jorm, 2000, p. 396). These definitions are good foundations; however, expanding upon and refining these definitions is recommended, given the connection between physical health and behavioral health.

\section{A New Definition of Behavioral Health Literacy}

Building off and expanding upon previous health, mental health, and behavioral health literacy definitions (Jorm, 2000; Sorensen et al., 2012; Willis \& O’Donohue, 2018), I propose the following behavioral health literacy definition to enhance one's literacy, whether one is a patient, family member, friend, colleague, professional, educator, provider, government official, or a member of the community. It is my contention that behavioral health literacy must use a systems-based analysis as opposed to reductionism to illustrate the interconnectedness among variables, including, but not limited to, biology, psychology, sociology, medical, legal, education, spirituality, social (e.g., relationships), epidemiology, financial, vocation, and nutrition.

\section{The Goal of Behavioral Health Literacy}

Behavioral health issues may stem from diverse variables, including, but not limited to, head trauma (Bogner et al., 2020), life stressors (Mumford et al., 2021; Sharma et al., 2019), communication disabilities (Stransky et al., 2020), parent-adolescent violence (Haber \& Toro, 2009), community violence (Voisin et al., 2016), adverse childhood experiences (Mehari et al., 2021; Warne et al., 2017), household incarceration (Fleming \& Nurius, 2020), deaf and hard-of-hearing (Anderson et al., 2018), and injuries (Schwatka et al., 2018). Additionally, inadequate behavioral health literacy may contribute to behavioral health problems or cause behavioral health problems to persevere (Benuto et al., 2019; Benuto et al., 2020; Green et al., 2020; O'Loughlin et al., 2019). In either case, or a combination thereof, the goal, therefore, is to educate everyone to improve behavioral health literacy and reduce stigma (or negative attitudes) related to behavioral health matters.

\section{The Objectives of Behavioral Health Literacy}

To achieve the goal, we divide behavioral health literacy into several domains to sharpen the definition's focus, and these domains are (a) behavioral health disorders, (b) terminology, (c) co-occurrence, (d) cognition, (e) readiness, (f) recovery, (g) behavioral health information, and ( $h$ ) attitude. There may be overlap between these domains; however, they should be treated separately to maintain focus. An individual who is literate in behavioral health will have the following abilities:

1. Behavioral Health Disorders. To understand, recognize, and explain the theories, signs, symptoms, types, causes, regression (i.e., decompensate), progression (i.e., from onset to death), and effects of disorders related to mental health (e.g., anxiety disorders, mood disorders, personality disorders, psychotic disorders, suicidal behavior, PTSD, etc.) and addiction (e.g., substances, gambling, pornography, sex, food, shopping, technology, etc.).

2. Terminology. To understand, delineate, and explain terminology related to behavioral health (e.g., illness, disorder, disease, behavioral health, mental health, mental illness, mental disorder, substance use disorder, addiction, dependency, co-dependency, tolerance, use, misuse, abuse, co-occurring disorder, recovery, relapse, etc.).

3. Co-occurrence. To understand and explain the relationship between physical health and behavioral health, and to understand co-occurring disorders. 
4. Cognition. To understand, recognize, and explain the theories, signs, symptoms, types, causes, and effects of cognitive distortions (e.g., all-or-nothing/polarized thinking, arbitrary inference/jumping to conclusions, attachment, being right, blame, catastrophizing, comparison, fallacy of control, detachment, dichotomous/black-and-white, disqualifying the positive, emotional reasoning/appeal to emotion, externalization of self-worth, fallacy of fairness, fallacy of change, fortune telling, heaven's reward, labeling/mislabeling, magical thinking, magnification, mental filter/negative filtering, mind reading, minimization, overgeneralization, perfectionism, personalization, reverse mind-reading, selective abstraction, "should"/"must" statements, and victimhood/victim mentality/self-pity/victim syndrome/victim complex, etc.); to understand the relationship between cognitive distortions, physical health, behavioral health, and overall quality of life; and to implement strategies to correct cognitive distortions (Clark \& Egan, 2015; Dobson \& Dobson, 2018; Freeman et al., 2005; Heffner, 2020; Winterowd et al., 2003).

5. Readiness. To understand, recognize, and explain the theories, elements, stages, and processes of change (e.g., precontemplation, contemplation, preparation, action, maintenance, and relapse), and to understand and implement strategies that promote internal motivation, readiness, and willingness to change.

6. Recovery. To understand, recognize, and explain the theories, elements, and stages of recovery (e.g., abstinence stage, repair stage, growth stage, etc.) and of relapse (e.g., emotional relapse, mental relapse, physical relapse, etc.); to understand and distinguish healthy and unhealthy recovery environments; to understand, recognize, and address internal and external triggers; to understand, recognize, and address cravings; to understand and distinguish protective and risk factors associated with recovery and relapse; and to understand and explain the levels of care, types of treatment, self-help interventions, and coping and self-care strategies, and the effectiveness of the aforementioned (Melemis, 2015).

7. Behavioral Health Information. To seek, access, understand, interpret, evaluate, and explain information on behavioral health, protective and risk factors for behavioral health, and information on determinants of behavioral health using a multifactorial or systems-based analysis; to make informed decisions on behavioral health matters; to seek and consult behavioral health professionals; to understand and discern the types and purposes of behavioral health professionals, certifications, and licenses; and to seek, access, understand, evaluate, distinguish, and explain the types and effectiveness of behavioral health services.

8. Attitude. To understand, recognize, and explain negative attitudes and stigma toward behavioral health and the effects thereof; to recognize and address negative attitudes and stigma in one's self and others; to educate, promote, and facilitate healthy and positive attitudes toward behavioral health; and to seek, access, understand, evaluate, discern, and explain myths and facts concerning behavioral health.

Curriculum specialists and policy makers should incorporate evidence-based instructional practices into behavioral health literacy programming. Role-playing (Dennison, 2011; Herbert \& Lohrmann, 2011), interactive technology-enhanced learning (Petty, 2013), collaborative and problem-based learning (HmeloSilver, 2004; Loes et al., 2017), project-based learning with digital storytelling (Hung et al., 2012), storytelling (Andrews et al., 2009; Boris \& Peterson, 2018), and case study (Bonney, 2015) are some examples of effective instructional strategies to achieve the previously mentioned objectives. Programming and literacy efforts should also incorporate people in behavioral health recovery to demonstrate that recovery is obtainable and to inspire and cultivate hope in individuals with and without behavioral health problems. 


\section{Conclusion}

Research and public interests have grown since the introduction of the behavioral health concept in the $1980 \mathrm{os}$. Behavioral health disorders remain a challenge and are anticipated to grow in the years to come. To tackle current and future behavioral health matters, a hearty and sharpened behavioral health literacy definition was proposed. The definition and concepts proposed herein are not meant to be rigid, however; they are organic and ever changing with continued research and exchange of ideas. Scholars, practitioners, and policy makers are encouraged to evaluate the proposed definition, expand or polish the definition, and continue the dialogue so a consensus for behavioral health literacy is achieved. A vigorous behavioral health literacy scale is also necessary, and this instrument should be tailored to the general public, not population specific, to improve behavioral health literacy across populations, cultures, languages, and nations. As we sow a strong behavioral health literacy foundation, both the individual and the community will reap benefits-lower costs, enhanced literacy, reduced use of services, positive attitudes, reduced stigma, improved overall wellness, and enhanced self-efficacy-for everyone. 


\section{References}

Aindrila, B. (2020). A nexus between environmental literacy, environmental attitude and healthy living. Environmental Science and Pollution Research, 27(6), 5922-5931. https:/doi.org/10.1007/s11356019-07290-5

Anderson, M. L., Chang, B.-H., \& Kini, N. (2018). Alcohol and drug use among deaf and hard-of-hearing individuals: A secondary analysis of NHANES 2013-2014. Substance Abuse, 39(3), 390-397. https://doi.org/10.1080/o8897077.2018.1442383

Andrews, D. H., Hull, T. D., \& Donahue, J. A. (2009). Storytelling as an instructional method: Definitions and research questions. Interdisciplinary Journal of Problem-Based Learning, 3(2). https://doi.org/10.7771/1541-5015.1063

Belar, C. D., McIntyre, T. M., \& Matarazzo, J. D. (2003). Health psychology. In D. K. Freedheim, \& I. B. Weiner (Eds.). Handbook of psychology (pp. 451-465). John Wiley \& Sons, Inc.

Benuto, L. T., Casas, J., Gonzalez, F., \& Newlands, R. (2020). The behavioral model of health: Education, behavioral health factors, and stigma as predictors of help-seeking attitudes. Community Mental Health Journal, 56, 1275-1283. https://doi.org/doi:10.1007/s10597-020-00601-y

Benuto, L. T., Gonzalez, F., Reinosa-Segovia, F., \& Duckworth, M. (2019). Mental health literacy, stigma, and behavioral health service use: The case of Latinx and non-Latinx whites. Journal of Racial and Ethric Health Disparities, 6, 1122-1130. https://doi.org/10.1007/s40615-019-00614-8

Bocchino, R. (1999). Emotional literacy: To be a different kind of smart. Corwin Press.

Bogner, J., Corrigan, J. D., Yi, H., Singichetti, B., Manchester, K., Huang, L., \& Yang, J. (2020). Lifetime history of traumatic brain injury and behavioral health problems in a population-based sample. Journal of Head Trauma Rehabilitation, 35(1), 43-50. https://doi.org/doi:10.1097/HTR.0000000000000488

Bonney, K. M. (2015). Case study teaching method improves student performance and perceptions of learning gains. Journal of Microbiology \& Biology Education, 16(1), 21-28. https://doi.org/10.1128/jmbe.v16i1.846

Boris, V., \& Peterson, L. (2018). Telling stories: How leaders can influence, teach, and inspire. https://www.harvardbusiness.org/insight/telling-stories-how-leaders-can-influence-teach-andinspire/

Brussat, F., \& Brussat, M. A. (1996). Spiritual literacy: Reading the sacred in everyday life. Simon \& Schuster.

Bryson, A. (1999). Healing: Mind, body, \& soul. Sterling Paperbacks.

Butler, M., Kane, R. L., McAlpine, D., Kathol, R. G., Fu, S. S., Hagedorn, H., \& Wilt, T. J. (2008). Integration of mental health/substance abuse and primary care (AHRQ Publication No. 09-E003). Agency for Healthcare Research and Quality.

Chytilova, H. (2018). Economic literacy and money illusion: An experimental perspective. Routledge.

Clark, G. I., \& Egan, S. J. (2015). The Socratic method in cognitive behavioural therapy: A narrative review. Cognitive Therapy and Research, 39(6), 863-879. https://doi.org/10.1007/s106o8-015-9707-3

Dennison, S. T. (2011). Interdisciplinary role play between social work and theater students. Journal of Teaching in Social Work, 31(4), 415-430. http://dx.doi.org/10.1080/o8841233.2011.597670

Dobson, D., \& Dobson, K. S. (2018). Evidence-based practice of cognitive-behavioral therapy (2nd ed.). Guilford Press. 
Egede, J., Campbell, J. A., Walker, R. J., Garacci, E., Dawson, A. Z., \& Egede, L. E. (2021). Relationship between physical and mental health comorbidities and COVID-19 positivity, hospitalization, and mortality. Journal of Affective Disorders, 283, 94-100. https://doi.org/10.1016/j.jad.2021.01.048

Fleming, C. M., \& Nurius, P. S. (2020). Incarceration and adversity histories: Modeling life course pathways affecting behavioral health. American Journal of Orthopsychiatry, 9o(3), 312-323. https://doi.org/10.1037/ortoooo436

Freeman, A., Felgoise, S. H., Nezu, C. M., Nezu, A. M., \& Reinecke, M. A. (2005). Encyclopedia of cognitive behavioral therapy. Springer.

Geboers, B., Reijneveld, S. A., Koot, J. A. R., \& de Winter, A. F. (2018). Moving towards a comprehensive approach for health literacy interventions: The development of a health literacy intervention model. International Journal of Environmental Research and Public Health, 15(6), 1268. https://doi.org/10.3390/ijerph15061268

Green, B., Jones, K., Lyerla, R., Dyar, W., \& Skidmore, M. (2020). Stigma and behavioral health literacy among individuals with proximity to mental health or substance use conditions. Journal of Mental Health, 3o(4), 481-487. https://doi.org/10.1080/09638237.2020.1713998

Haber, M. G., \& Toro, P. A. (2009). Parent-adolescent violence and later behavioral health problems among homeless and housed youth. American Journal of Orthopsychiatry, 79(3), 305-318. https://doi.org/10.1037/aoo17212

Hall, J. R. C. (1894). A concise Anglo-Saxon dictionary. MacMillan.

Heffner, J. (2020). Cognitive behavioral therapy: Techniques you need to free yourself from anxiety, depression, phobias, and intrusive thoughts. Avoid harmful meds by retraining your brain with $C B T$. Educational Books.

Herbert, P. C., \& Lohrmann, D. K. (2011). It's all in the delivery! An analysis of instructional strategies from effective health education curricula. Journal of School Health, 81(5), 258-264. https://doi.org/10.1111/j.1746-1561.2011.00586.x

Hmelo-Silver, C. E. (2004). Problem-based learning: What and how do students learn? Educational Psychology Review, 16(3), 235-266. https://doi.org/10.1023/B:EDPR.0000034022.16470.f3

Hobbs, R., \& Jensen, A. (2009). The past, present, and future of media literacy education. Journal of Media Literacy Education, 1(1), 1-11. https://digitalcommons.uri.edu/jmle/vol1/iss1/1

Holmberg, A., Jensen, P., \& Vetere, A. (2021). Spirituality-a forgotten dimension? Developing spiritual literacy in family therapy practice. Journal of Family Therapy, 43(1), 78-95. https://doi.org/10.1111/1467-6427.12298

Huhta, A., Hirvonen, N., \& Huotari, M. (2018). Health literacy in web-based health information environments: Systematic review of concepts, definitions, and operationalization for measurement. Journal of Medical Internet Research, 2O(12), e10273. https://doi.org/10.2196/10273

Hung, C. M., Hwang, G. J., \& Huang, I. (2012). A project-based digital storytelling approach for improving students' learning motivation, problem-solving competence and learning achievement. Journal of Educational Technology \& Society, 15(4), 368-379.

Jorm, A. F. (2000). Mental health literacy: Public knowledge and beliefs about mental disorders. The British Journal of Psychiatry, 177(5), 396-401. https://doi.org/10.1192/bjp.177.5.396

Jorm, A. F., Korten, A. E., Jacomb, P. A., Christensen, H., Rodgers, B., \& Pollitt, P. (1997). "Mental health literacy:" A survey of the public's ability to recognise mental disorders and their beliefs about the effectiveness of treatment. The Medical Journal of Australia, 166(4), 182-186.

https://doi.org/10.5694/j.1326-5377.1997.tb140071.x 
King, U. (2013). The spiritual potential of childhood: Awakening to the fullness of life. International Journal of Children's Spirituality, 18(1), 4-17. https://doi.org/10.1080/1364436X.2013.776266

Lee, H. Y., Hwang, J., Ball, J. G., Lee, J., \& Albright, D. L. (2020). Is health literacy associated with mental health literacy? Findings from mental health literacy scale. Perspectives in Psychiatric Care, 56(2), 393-400. https://doi.org/10.1111/ppc.12447

Lewis, C. T., \& Short, C. (1879). A Latin dictionary: Founded on Andrews' edition of Freund's Latin dictionary. Clarendon Press.

Liu, C., Wang, D., Liu, C., Jiang, J., Wang, X., Chen, H., Ju, X., \& Zhang, X. (2020). What is the meaning of health literacy? A systematic review and qualitative synthesis. Family Medicine and Community Health, 8(2), eooo351. https://doi.org/10.1136/fmch-2020-000351

Loes, C. N., An, B. P., Saichaie, K., \& Pascarella, E. T. (2017). Does collaborative learning influence persistence to the second year of college? The Journal of Higher Education, 88(1), 62-84. https://doi.org/10.1080/00221546.2016.1243942

Logan, R. A., \& Siegel, E. R. (Eds.). (2017). Health literacy: New directions in research, theory, and practice. IOS Press.

Mancini, M. A. (2021). Integrated behavioral health practice. Springer.

Mansfield, R., Patalay, P., \& Humphrey, N. (2020). A systematic literature review of existing conceptualisation and measurement of mental health literacy in adolescent research: Current challenges and inconsistencies. BMC Public Health, 2O(1), 607. https://doi.org/10.1186/s12889-02008734-1

Matarazzo, J. D. (1980). Behavioral health and behavioral medicine: Frontiers for a new health psychology. American Psychologist, 35(9), 807-817. https://doi.org/10.1037/0003-066X.35.9.807

Mehari, K., Iyengar, S., Schneider, M., Berg, K., \& Bennett, A. (2021). Adverse childhood experiences among children with neurodevelopmental delays: Relations to diagnoses, behavioral health, and clinical severity. Journal of Clinical Psychology in Medical Settings. https://doi.org/10.1007/s10880-02109769-1

Melemis, S. M. (2015). Relapse prevention and the five rules of recovery. Yale Journal of Biology and Medicine, 88(3), 325-332.

Milner, H. (2002). Civic literacy: How informed citizens make democracy work. University Press of New England.

Mumford, E. A., Liu, W., \& Taylor, B. G. (2021). Profiles of U.S. law enforcement officers' physical, psychological, and behavioral health: Results from a nationally representative survey of officers. Police Quarterly. https://doi.org/10.1177/1098611121991111

National Academies of Sciences, Engineering, and Medicine. (2019). The intersection of behavioral health, mental health, and health literacy: Proceedings of a workshop. The National Academies Press. https://doi.org/10.17226/25278

O’Connor, M., \& Casey, L. (2015). The Mental Health Literacy Scale (MHLS): A new scale-based measure of mental health literacy. Psychiatry Research, 229(1-2), 511-516. https://doi.org/10.1016/j.psychres.2015.05.064

O'Connor, M., Casey, L., \& Clough, B. (2014). Measuring mental health literacy-a review of scale-based measures. Journal of Mental Health, 23(4), 197-204. https://doi.org/10.3109/o9638237.2014.910646 
Ohrnberger, J., Fichera, E., \& Sutton, M. (2017). The relationship between physical and mental health: A mediation analysis. Social Science \& Medicine, 195, 42-49.

https://doi.org/10.1016/j.socscimed.2017.11.008

O’Loughlin, K., Donovan, E. K., Radcliff, Z., Ryan, M., \& Rybarczyk, B. (2019). Using integrated behavioral healthcare to address behavioral health disparities in underserved populations. Translational Issues in Psychological Science, 5(4), 374-389. https://doi.org/10.1037/tpsoooo213

Organization for Economic Co-operation and Development. (2005). Improving financial literacy: Analysis of issues and policies. OECD.

Osborn, D. P. J. (2001). The poor physical health of people with mental illness. Western Journal of Medicine, 175(5), 329-332. https://doi.org/10.1136/ewjm.175.5.329

Peek, C. J., \& National Integration Academy Council. (2014). Lexicon for behavioral health and primary care integration: Concepts and definitions developed by expert consensus (AHRQ Pub. No.13-IPoo1-EF). Agency for Healthcare Research and Quality.

Peerson, A., \& Saunders, M. (2009). Health literacy revisited: What do we mean and why does it matter? Health Promotion International, 24(3), 285-296. https://doi.org/10.1093/heapro/dapo14

Petty, J. (2013). Interactive, technology-enhanced self-regulated learning tools in healthcare education: A literature review. Nurse Education Today, 33(1), 53-59. https://doi.org/10.1016/j.nedt.2012.06.008

Pollard, N., \& Sakellariou, D. (Eds.). (2012). Politics of occupation-centred practice: Reflections on occupational engagement across cultures. Wiley-Blackwell.

Robson, D., \& Gray, R. (2007). Serious mental illness and physical health problems: A discussion paper. International Journal of Nursing Studies, 44(3), 457-466. https://doi.org/10.1016/j.ijnurstu.2006.07.013

Scholz, R. W. (2011). Environmental literacy in science and society: From knowledge to decisions. Cambridge University Press.

Schwatka, N. V., Shore, E., Atherly, A., Weitzenkamp, D., Dally, M. J., Brockbank, C. v. S., Tenney, L., Goetzel, R. Z., Jinnett, K., McMillen, J., \& Newman, L. S. (2018). Reoccurring injury, chronic health conditions, and behavioral health: Gender differences in the causes of workers' compensation claims. Journal of Occupational and Environmental Medicine, 6o(8), 710-716. https://doi.org/10.1097/JOM.0000000000001301

Scott, D. (2000). Reading educational research and policy. Routledge. https://doi.org/10.4324/9780203487525

Scott, D., \& Happell, B. (2011). The high prevalence of poor physical health and unhealthy lifestyle behaviours in individuals with severe mental illness. Issues in Mental Health Nursing, 32(9), 589-597. https://doi.org/10.3109/01612840.2011.569846

Scott, K. M., Lim, C., Al-Hamzawi, A., Alonso, J., Bruffaerts, R., Caldas-de-Almeida, J. M., Florescu, S., de Girolamo, G., Hu, C., de Jonge, P., Kawakami, N., Medina-Mora, M. E., Moskalewicz, J., NavarroMateu, F., O’Neill, S., Piazza, M., Posada-Villa, J., Torres, Y., \& Kessler, R. C. (2016). Association of mental disorders with subsequent chronic physical conditions: World mental health surveys from 17 countries. JAMA Psychiatry, 73(2), 150-158. https://doi.org/10.1001/jamapsychiatry.2015.2688

Scott, K. M., Von Korff, M., Alonso, J., Angermeyer, M. C., Bromet, E., Fayyad, J., de Girolamo, G., Demyttenaere, K., Gasquet, I., Gureje, O., Haro, J. M., He, Y., Kessler, R. C., Levinson, D., MedinaMora, M. E., Oakley Browne, M., Ormel, J., Posada-Villa, J., Watanabe, M., \& Williams, D. (2009). Mental-physical co-morbidity and its relationship with disability: Results from the world mental health surveys. Psychological Medicine, 39(1), 33-43. https://doi.org/10.1017/Soo33291708003188 
Sharma, S., Mustanski, B., Dick, D., Bolland, J., \& Kertes, D. A. (2019). Protective factors buffer life stress and behavioral health outcomes among high-risk youth. Journal of Abnormal Child Psychology, 47(8), 1289-1301. https://doi.org/10.1007/s10802-019-00515-8

Simonds, S. K. (1974). Health education as social policy. Health Education Monographs, 2(1 suppl), 1-10. https://doi.org/10.1177/10901981740020S102

Sorensen, K., Van den Broucke, S., Fullam, J., Doyle, G., Pelikan, J. M., Slonska, Z., Brand, H., \& Consortium Health Literacy Project European (HLS-EU). (2012). Health literacy and public health: A systematic review and integration of definitions and models. BMC Public Health, 12(1), 80. https://doi.org/10.1186/1471-2458-12-80

Spante, M., Hashemi, S. S., Lundin, M., \& Algers, A. (2018). Digital competence and digital literacy in higher education research: Systematic review of concept use. Cogent Education, 5(1). https://doi.org/10.1080/2331186X.2018.1519143

Spiker, D. A., \& Hammer, J. H. (2019). Mental health literacy as theory: Current challenges and future directions. Journal of Mental Health, 28(3), 238-242. https://doi.org/10.1080/09638237.2018.1437613

Stair, R. M., \& Reynolds, G. W. (2016). Principles of information systems (12th ed.). Cengage Learning.

Steiner, C., \& Perry, P. (1999). Achieving emotional literacy. Bloomsbury.

Stransky, M. L., Oshita, J. Y., \& Morris, M. A. (2020). Prevalence of behavioral health problems among adults with and without communication disabilities. The Journal of the American Board of Family Medicine, 33(6), 932-941. https://doi.org/10.3122/jabfm.2020.06.200216

Substance Abuse and Mental Health Services Administration. (2014). A treatment improvement protocol. Trauma-informed care in behavioral health services (HHS Publication No. SMA 13-4801). SAMHSA.

United Nations Educational, Scientific and Cultural Organization. (2017). Reading the past, writing the future: Fifty years of promoting literacy. UNESCO.

United Nations Office on Drugs and Crime. (2021). World drug report 2021. United Nations.

Voisin, D. R., Patel, S., Hong, J. S., Takahashi, L., \& Gaylord-Harden, N. (2016). Behavioral health correlates of exposure to community violence among African-American adolescents in Chicago. Children and Youth Services Review, 69, 97-105. https://doi.org/10.1016/j.childyouth.2016.08.006

Walker, E. R., \& Druss, B. G. (2018). Mental and addictive disorders and medical comorbidities. Current Psychiatry Reports, 20, 86. https://doi.org/10.1007/s11920-018-0956-1

Warne, D., Dulacki, K., Spurlock, M., Meath, T., Davis, M. M., Wright, B., \& McConnell, K. J. (2017). Adverse childhood experiences (ACE) among American Indians in South Dakota and associations with mental health conditions, alcohol use, and smoking. Journal of Health Care for the Poor and Underserved, 28(4), 1559-1577. https://doi.org/10.1353/hpu.2017.0133

Willis, B., \& O’Donohue, W. T. (2018). The neglected constructs of health literacy, shared decision-making, and patient-centered care in behavioral health: An integrated model. In M. P. Duckworth, \& W. T. O'Donohue (Eds.). Behavioral Medicine and integrated care: Efficient delivery of effective treatments (pp. 147-174). Springer.

Winterowd, C., Beck, A. T., \& Gruener, D. (2003). Cognitive therapy with chronic pain patients. Springer.

Weare, K. (2004). Developing the emotionally literate school. SAGE.

Wei, Y., McGrath, P. J., Hayden, J., \& Kutcher, S. (2015). Mental health literacy measures evaluating knowledge, attitudes and help-seeking: A scoping review. BMC Psychiatry, 15(291), 291. https://doi.org/10.1186/s12888-015-0681-9 
World Health Organization. (n.d.). Mental health. www.who.int/health-topics/mental-health

World Health Organization. (2020). The impact of COVID-19 on mental, neurological, and substance use services: Results of a rapid assessment. World Health Organization. https://www.who.int/publications/i/item/978924012455

Zarcadoolas, C., Pleasant, A. F., \& Greer, D. S. (2006). Advancing health literacy: A framework for understanding and action. Jossey-Bass. issues. JSBHS articles include peer-reviewed research reports, brief reports, comprehensive literature reviews, book reviews, and student research. 